\title{
THE DEMONSTRATION OF THE TUBERCLE BACILLUS IN THE PULMONARY TUBERGULOSIS OF CHILDHOOD
}

\author{
BY \\ SETON CAMPBELL, M.A., M.B. \\ (From the Princess Elizabeth of York Hospital for Children, London.)
}

The diagnosis of pulmonary tuberculosis in children is notoriously difficult to establish, and this is in great part due to the rarity with which the tubercle bacillus is found. In the adult reliance is placed on the discovery of the bacillus in the sputum, and, unless this is done, the diagnosis must always remain in some doubt. The presence of the tubercle bacillus, if it can be demonstrated by any one of a variety of methods, clinches the diagnosis and can leave little doubt in the mind of even the most sceptical. Hence the finding of the bacillus must ever be a point of great importance, not only so that the diagnosis may be placed beyond doubt but in order that adequate treatment may be obtained; for the tuberculosis officer, armed with the fact that the bacillus has been seen, is able not only to provide more prolonged sanatorium treatment, but is better able to prevail on contacts to subject to examination. In the child, however, the obtaining of sputum for examination has always been a difficulty and there are many devices which have been introduced to overcome this.

In 1898 Mernier $^{1}$ made the first attempt to demonstrate the tubercle bacillus in swallowed sputum by means of stomach lavage, and this has within recent years become the favourite method. A high percentage of positive results has been reported by this method. Poulsen ${ }^{2}$ obtained fiftythree positives out of 110 tuberculous children and Wallgren ${ }^{3}$ examined the fasting stomach contents in thirty-seven children with erythema nodosum and positive Mantoux reactions, and was able to demonstrate the bacillus in seventeen instances, while Armand-Delille ${ }^{4}$ reports 30 per cent. positive results in 110 tuberculous children. In 1904 Leonard Findlay ${ }^{5}$ suggested attempting to obtain the sputum while it was in the pharynx and before it had been swallowed, and recently Nalbant ${ }^{6}$ and Mishulow and her coworkers $^{7}$ have affirmed that repeated examination of the faeces will yield as high a percentage of positives as will stomach lavage.

\section{Present investigation}

The present communication reports an investigation of the relative advantages of the various methods of demonstrating the tubercle bacillus, and at the same time to attempt to establish the comparative value of the 
various aids to diagnosis. A series of fifty suspect children were investigated as follows. A careful history was taken, especially as to contact with open tuberculosis, and a thorough physical examination was carried out, including radiology of the chest, while attempts to discover the tubercle bacillus were made by each of the following three methods:-

(i) Examination of the sputum when this was obtainable.

(ii) Examination of the faeces.

(iii) Stomach lavage and treatment of the contents by:-

(a) Examination of a direct smear.

(b) Culture on Lowenstein-Jensen medium.

(c) Guinea-pig inoculation.

Those children were considered suspect in whom there was a history of contact with an open case of tuberculosis, those who were under four years of age and gave a positive Mantoux reaction, and those who on clinical grounds such as cough, wasting, pain in the chest or erythema nodosum suggested active tuberculosis.

The same procedure was adopted in all cases, and details of the results obtained are given in the following tables. The cases are arranged in order of age. Table 1 gives details of the fifty cases examined, while table 2 shows particulars of those cases which were found to be positive.

\section{Discussion of results}

Age.-A summary of the tables shows that fourteen of the fifty children were under three years of age and of these eight or 57 per cent. were bacilli carriers, while thirty-six were over three years and yielded only four positives (11 per cent.). These findings compare with Poulsen's ${ }^{2}$ results in a series of 110 cases, in which sixty-two were under three years and of these forty-one or 66 per cent. were positive, while forty-eight were over three and gave twelve positives (25 per cent.). It would appear, therefore that, given a tuberculous child, the younger it is the more likely is it that the tubercle bacillus will be isolated by some method, although the technique is necessarily more difficult. This finding is in keeping with the belief that the disease is more severe and more widespread in the younger children; but it may really be due to the fact that the disease is at an earlier stage and therefore more likely to be active.

Contact.-Contact plays a large part in the spread of tuberculosis. Armand-Delille ${ }^{8}$ from his statistics asserts that 60 per cent. of children with tuberculous parents develop the disease before the death of the parents. He further states that of those 60 per cent. fully two-thirds die from one of the acute forms, either miliary tuberculosis or meningitis, and that only one-third present any localization. In the present series of fifty cases, nine contact children were examined who appeared to be quite well; they were well nourished and their mothers were quite satisfied as to their progress. Of these nine children seven belonged to one family in which the mother 
TUBERCLE BACILLUS IN PULMONARY TUBERCULOSIS

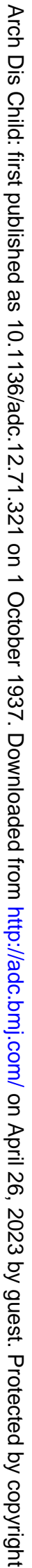


TUBERCLE BACILLUS IN PULMONARY TUBERCULOSIS 325

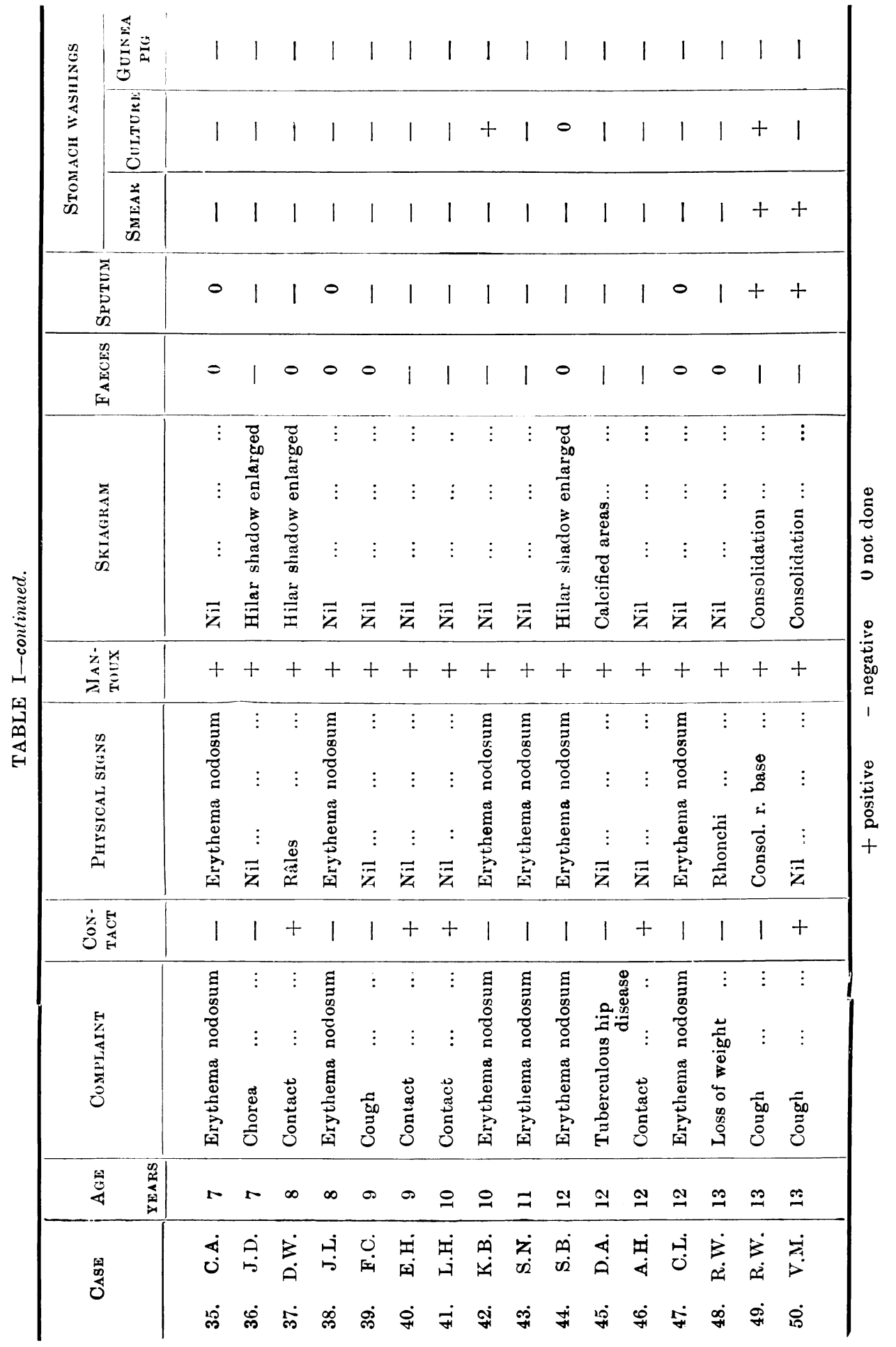


suffered from open tuberculosis with positive sputum. All of the children in the family reacted positively to Mantoux's test although, as already noted, physical examination was negative. The youngest child showed enlarged uncalcified mediastinal glands on x-ray examination. Sputum was not obtained from the younger ones and was negative in the older, but from the stomach washings of the two youngest, aged three and one year and three months respectively, tubercle bacilli were grown in four-and-a-half weeks. Of the twelve cases which were proved positive (table 2) a history of contact was obtained in six instances (50 per cent.).

Physical signs.-It is worthy of comment that physical signs in the chest were not as valuable in indicating active mischief as might have been anticipated. But when the physical signs indicated a gross lesion, e.g., consolidation, the correlation with the presence of living tubercle bacilli in the sputum and more particularly in the younger children was fairly close. Of the eight children presenting consolidation on physical examination only five or 62 per cent. gave positive findings, but of the four under three years of age all were positive. Râles and rhonchi less seldom were evidence of active disease as only two out of nine cases gave positive findings, but again it may be stressed that of the three children under three years of age two were positive. Physical signs other than those in the chest may suggest active pulmonary disease. For example, in one child aged seven months an enlarged spleen was the only evidence of a miliary tuberculosis disclosed by radiology and confirmed by finding the tubercle bacilli in the stomach washings.

Seven patients with erythema nodosum, who gave a positive Mantoux test, were included in the series. In this condition some previous workers ${ }^{3,9}$ have recorded that the tubercle bacillus is found not infrequently in the stomach contents. All these children were over three years of age and in only one of them was the tubercle bacillus discovered. In this particular case physical and radiological examination of the chest was negative; indeed in this series of examples of erythema nodosum the only abnormal finding was the presence of a questionable increased hilar shadow in two instances. Three cases of pleural effusion were investigated but in none of these was the tubercle bacillus demonstrated in either the pleural fluid or the stomach washings.

Radiography.- - It is generally recognized that radiology not infrequently discloses the presence of mischief in the lung not apparent on physical examination, and that the radiological evidence is usually much in excess of the physical signs. There are serious limitations to even this method of investigation. All shadows do not necessarily indicate tuberculous disease. There is the question of the significance of the enlarged hilar shadow and as McPhedran ${ }^{10}$ has pointed out,small and even moderately enlarged caseous tracheo-bronchial glands, which form the majority of the lesions of these glands, are not demonstrable radiologically. It is only in the event of 
calcification or if they are so much enlarged as to bulge outside the mediastinum that they will show up, and in these circumstances there is usually other evidence to be found in the lung field. In this series an enlarged hilar shadow alone was ignored unless there was evidence of a primary focus. But in spite of this restriction the bacillus was only found in one out of nine cases showing a Ghon focus and enlarged hilar shadow.

All the examples of miliary tuberculosis revealed the presence of the tubercle bacillus. Of seven cases showing in the skiagram consolidation of one or other lobe four or 57 per cent. were positive for the tubercle bacillus, but it is worthy of note that of the children over three years of age only 75 per cent. were positive whereas in children under three in whom consolidation was detected the tubercle bacillus was recovered in all cases. It would seem therefore that not only radiological evidence, unless unequivocal as in miliary disease, but also physical signs, are only of significance when taken in conjunction with the tender age of the child. The above facts are shown in tabular form below.

TABLE 3.

RADIOGRAPIIY

\begin{tabular}{|c|c|c|c|c|c|c|}
\hline RADIOLOGICAL AP & PEAT & NCES & & $\begin{array}{c}\text { No. of } \\
\text { CASES }\end{array}$ & $\begin{array}{l}\text { No. of } \\
\text { Positives }\end{array}$ & $\begin{array}{c}\text { PER CENT. } \\
\text { POSITIVe }\end{array}$ \\
\hline Miliary tuberculosis & $\ldots$ & $\ldots$ & $\ldots$ & 3 & 3 & 100 \\
\hline Consolidation & $\ldots$ & $\ldots$ & $\ldots$ & 8 & 5 & 62 \\
\hline ' Epituberculosis' & $\ldots$ & $\ldots$ & $\ldots$ & 2 & 1 & 50 \\
\hline Hilar shadow enlarged & $\ldots$ & $\ldots$ & $\ldots$ & 9 & 1 & 11 \\
\hline Pleural effusion $\ldots$ & $\ldots$ & $\ldots$ & $\ldots$ & 3 & 0 & 0 \\
\hline Nil ... & $\ldots$ & $\ldots$ & $\ldots$ & 24 & 2 & 8 \\
\hline
\end{tabular}

Physical, sigins

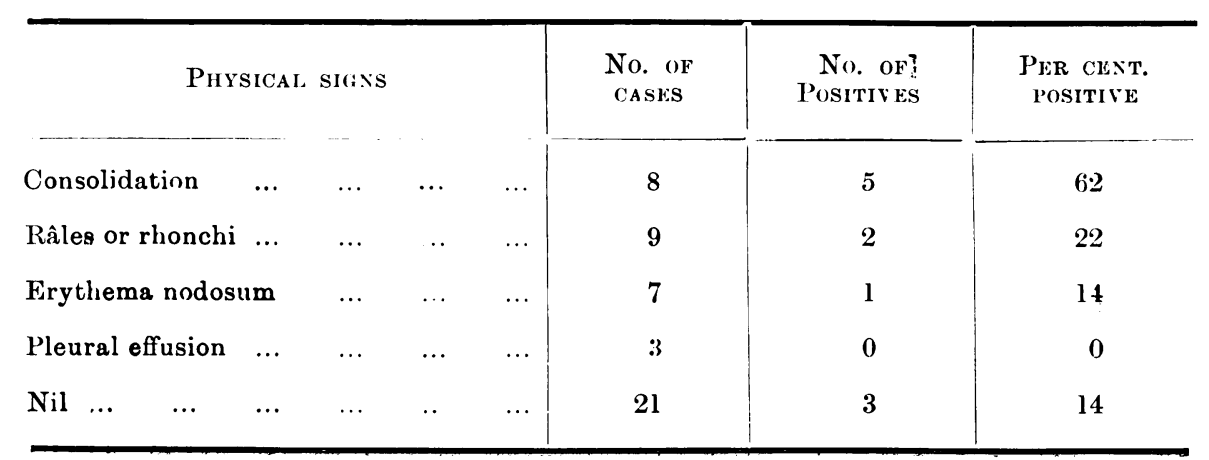


Isolation of the tubercle bacillus

Faeces.--Mishulow ${ }^{7}$, Nalbant ${ }^{6}$ and others believe that examination of the faeces can yield as many positives as gastric lavage. Accordingly in twenty-six of the earlier cases the faeces were examined for the tubercle bacillus using the following technique:-

A portion of the faeces, preferably one containing blood or muco-pus, was picked up and emulsified in saline. This was centrifuged for thirty seconds to remove the coarser debris, the supernatant fluid was poured off and an equal quantity of 90 per cent. alcohol added. This was again centrifuged at high speed for three minutes. The supernatant fluid was again poured off, and from the sediment smears were made and stained for tubercle bacilli.

In this small series the results were not encouraging, as in no case was the tubercle bacillus found in the faeces when it could not be demonstrated in either the sputum or in the stomach washings, while in six cases examination of the faeces failed to reveal the bacillus when it was demonstrated in either the sputum or stomach washing. In the later cases therefore the faeces were not examined.

Sputum. - Findlay ${ }^{5}$ described a procedure which consists of swabbing the back of the pharynx with a finger round which is a piece of gauze. If this is done during a fit of coughing so much the better, although the manipulation usually causes coughing, and the material obtained is spread on a slide and stained with Ziehl-Nielsen. In this series the procedure was only occasionally adopted but in one case was beautifully demonstrated and is worth considerable further trial. As Cowper has said that there must be at least 100,000 tubercle bacilli per c.c. to be detected, the value of working with a concentrated material such as sputum is therefore apparent. In the present series of fifty cases the sputum was obtained from thirty-five, but it will be noted that from the twenty cases under four years of age it was only obtainable in ten. Of the twelve positive cases (table 2) from which the tubercle bacillus was isolated by one method or another, the sputum was obtained in nine instances and in five of these the bacillus was demonstrated.

Gastric lavage.-All the children were subjected to stomach lavage, a process which they dislike intensely, and for this reason it was not repeated more often than was necessary.

Poulsen $^{2}$ in his fifty-three positive results demonstrated the tubercle bacillus at the first lavage in thirty-eight cases, in the second lavage in twelve, in the third in two cases, and in the fourth in one. Both he and Mishulow ${ }^{7}$ agree that the search should be repeated a number of times if negative.

In the present series when the specimen from the stomach was abundant the lavage was not repeated. Many of the cases were only admitted to hospital for one night for the purpose, and so the lavage could not be carried out more than once. If, however, the specimen was inadequate, the patient's stomach was washed out again the following morning and the washings pooled. 
The procedure was as follows:-On waking, the child was made to cough and, if any sputum was expectorated, this was kept for direct examination. A medium bore stomach tube was then passed by mouth and the contents washed out with 200 c.c. of distilled water. This was collected in a sterile bowl and delivered to the laboratory. Here a direct smear was made, part was treated for culture, and some was injected into a guinea-pig.

(a) Direct smear. The stomach washings were poured into a Petri dish and examined on a dark background; a likely caseous area was picked up and a smear made. The method advocated by Armand-Delille and Vibert $^{11}$ of homogenizing the contents before making a smear as it increased their number of positives by 20 per cent., was not adopted on this work because it entails considerably extra time and this was not available. The direct smear as used was found of considerable value-as of the twelve positive cases the tubercle bacillus was demonstrated in this way in seven instances.

(b) Culture. For culture the stomach contents were treated in the following manner. One c.c. of the thicker mucus was taken up with a pipette into a test tube and to this was added 4 c.c. of 4 per cent. soda. It was then incubated at $37^{\circ} \mathrm{C}$. for twenty minutes, and was shaken at five-minute intervals. By this time the mucus was dissolved and presumably the organisms, other than tubercle bacilli, were killed. It was then neutralized to phenol red with normal hydrochloric acid and centrifuged at high speed for one hour. The supernatant fluid was then decanted and the sediment sown on Loewenstein-Jensen medium. This medium was obtained commercially and was supplied in the screw-stopped bottles described by McCartney ${ }^{12}$ which has the advantage of preventing evaporation over a long period of incubation. Subcultures gave rather a poor growth, and it was found that, once the growth had appeared, if the cultures were kept in the incubator the medium tended to liquefy and sink to the bottom of the tube.

The results with this medium and method of treating the stomach contents were gratifying. Of the positive cases ten were treated by this method and eight gave a growth of tubercle bacilli in from three to five weeks. Usually in three weeks a small wart-like, white or brownish, discrete growth appeared, followed by other similar ones. Smears showed typical tubercle bacilli. An emulsion from a typical growth was injected into a guinea-pig and a rabbit. The guinea-pig died in six-and-a-half weeks and tubercle bacilli were found in smears made from the spleen and lungs. The rabbit was killed after three months and tubercle bacilli were also isolated.

(c) Guinea-pig inoculation. For this the remains of the stomach washings were taken up into a centrifuge tube and spun for an hour. One c.c. was then removed from the top of the tube, the supernatant fluid decanted and the top c.c. added to the sediment. This is done on the principle that some tubercle bacilli are carried with a little mucus to the top of the tube during the centrifuging. The whole was made up to 5 c.c. with normal saline, and of this 0.5 c.c. was injected into the medial aspect of the guinea-pig's thigh. Magath ${ }^{13}$ has described a method for accelerating the diagnosis in an infected pig. He injects the animal with 0.5 c.c. of old tuberculin four weeks after the inoculation, and finds that if infection has already taken place death will occur within forty-eight hours. If the animal does not die the chances of it having tuberculosis are about 1 in 30 . 
In fifteen of the present series of cases two guinea-pigs were injected from each case, and after a period of four weeks one of the animals was injected with 0.5 c.c. old tuberculin. In the cases subjected to this procedure death of the animals was not accelerated and both the injected and control pig had to be killed at the end of six weeks. This small number therefore does not confirm Magath's work.

The pigs were always killed at the end of six weeks and the positive ones usually showed gross tuberculosis. Sections of the spleen and sometimes of the glands and lungs, were cut in all cases, and only those which showed tuberculosis microscopically were considered positive.

Out of the twelve positive cases (table 2) animal inoculation was performed in ten, and from these the pig was infected in five instances. Twice in the course of a year epidemics of what on post-mortem examination proved to be capillary bronchitis or broncho-pneumonia, broke out and carried off a number of pigs. In some cases the inoculations were repeated, but in most the experiment had to be counted a failure if the pig died within three weeks of inoculation. This constitutes a serious disadvantage and is a point against relying entirely on animal inoculation for a diagnosis.

\section{General discussion}

In the efforts to demonstrate the tubercle bacillus in pulmonary tuberculosis the greatest proportion of success was obtained by culture of the stomach washings. Other workers have also obtained good results with culture on Loewenstein-Jensen medium. Evelyn Holmes ${ }^{14}$, for example, obtains such a high proportion of positive findings in her series that she states that a negative culture in her hands has a considerable diagnostic value. Poulsen, Jensen and Husted ${ }^{15}$ compare their results with the various methods of treating the stomach washings. From fifteen tuberculous patients they were able to demonstrate the bacillus in eleven instances. Five out of twenty-seven specimens were positive by direct smear (18.5 per cent.), but of the eighteen specimens cultured nine grew the tubercle bacillus (50 per cent.), while of the twenty-five animals inoculated nineteen were infected with tuberculosis (76 per cent.).

In the present series of fifty cases, out of the twelve examples in which the tubercle bacillus was eventually isolated, culture on Loewenstein-Jensen medium was carried out in ten instances and was positive in eight, i.e., 80 per cent. It should, however, be mentioned that of the above twelve positives, sputum was obtained in eight instances and of these five, or 63 per cent., disclosed the presence of the bacillus. In addition to the lower proportion of positive results from examination of the sputum the difficulty, indeed the impossibility, of always obtaining the sputum must be taken into consideration. Although, as previously mentioned, the children resent lavage of the stomach, the swallowed sputum can always be obtained.

Direct smear of the stomach washings was much less frequently positive than was culture. In the ten positive cases in which culture was carried out the organism was only found by direct smear in five, i.e., 50 per cent. as 
against 80 per cent. by culture. Animal inoculation was also less frequently positive as in only five out of the ten cases, i.e., 50 per cent., was the organism isolated. The risk of the animals dying from intermittent disease, as well as the long time required for the test, are further drawbacks.

\section{Summary}

(1) In fifty children suspected of pulmonary tuberculosis the tubercle bacillus was found in sputum, faeces, or stomach washings in twelve instances.

(2) Sputum was obtained in nine of the twelve positive cases and in five of these the tubercle bacillus was discovered.

(3) Faeces were examined in a number of the cases but in no case was the bacillus found by this method when it could not be demonstrated by one of the others.

(4) In a direct smear of the stomach washings the tubercle bacillus was found in seven instances. In ten of the twelve positive cases the stomach washings were treated by guinea-pig inoculation and by culture, and the tubercle bacillus was isolated from the guinea-pig in five instances and by culture in eight.

(5) Owing to the possibility of epidemics amongst the guinea-pigs attention is drawn to the danger of relying entirely on this method of diagnosis.

(6) Whatever the lesion the tubercle bacillus is found most frequently in children under three, and this in spite of the greater difficulty of the examination at this period of life.

Thanks are due to the staff of the Princess Elizabeth of York Hospital for Children, Shadwell, for permission to use their cases and especially to Dr. Leonard Findlay for his kindly advice and to Mr. N. Smith for much help in the laboratory.

\section{REFERENCES}

1. Mernier, H., Presse méd., Paris, 1898, II, 81.

2. Poulsen, V., Amer. J. Dis. Child., Chicago, 1931, XLI, 783.

3. Wallgren, A., loc. cit., 816.

4. Armand-Delille, P. F., ibid., 1927, XXXIV, 547.

5. Findlay, L., Arch. Pediat., New York, 1904, XXI, 126.

6. Nalbant, J. P., Amer. Rev. Tuberc., New York, 1934, XXIX, 481.

7. Mishulow, L., et al., loc. cit., 471.

8. Armand-Delille, P. F., Brit. J. Tuberc., London, 1935, XXIX, 2.

8. Collis, W. R. F., Quart. J. Med., Oxford, 1932, XXV, 141.

10. McPhedran, F. M., Amer. Rev. Tuberc., New York, 1929, XX, 532.

11. Armand-Delille, P. F., \& Vibert, J., Presse méd., Paris, 1927, XXVI, 402.

12. McCartney, J. E., Lancet, London, 1933, ii, 433.

13. Magath, T. B., Amer. J. Med. Sci., Philadelphia, 1934, CLVIII, 403.

14. Holmes, E., J. Clin. Res., London, 1935, XXI, 92.

15. Poulsen, V., Jensen, K. A., \& Husted, E., Am. J. Dis. Child., Chicago, 1929, XXXVII, 900, 